\title{
Preschool and first grade teachers' perceptions on working together to enhance literacy
}

\author{
Zoi Apostolou*, Nektarios Stellakis** \\ *University of Patras, Grece; aposotlo@upatras.gr \\ ** University of Patras, Grece; nekstel@upatras.gr
}

\begin{abstract}
The purpose of this research is to investigate the perceptions of kindergarten teachers and first-grade primary school teachers about their cooperation regarding literacy practices and their enhancement. The need for cooperation, the potential for co-operation, how to achieve it, as well as its benefits for enhancing literacy, are the key questions explored. The research is part of a broader study of the relationships between natural / early and conventional / school literacy, the teachers' perceptions of the possibility of integration of language curricula, as well as practices resulting from the study of curricula. The data were collected through a questionnaire sample of 632 teachers who were separated into two groups, 326 kindergarten teachers and 306 teachers teaching the year of the process in the first grade of Greek elementary schools. The results showed that kindergarten teachers were more positive about the need for co-operation on literacy practices, but first-grade primary school teachers believed more in their co-operation. Kindergarten teachers and first-grade primary school teachers agree on the need for joint actions, with teachers considering as significant constraints the co-location of school units, the lack of common time, and the pressure of "course material".
\end{abstract}

Keywords: literacy, kindergarten, primary school, teachers' perceptions, co-operation, literacy learning practices, early literacy, school literacy

\section{Theoretical background}

When attempting a theoretical and research approach to enhancing natural literacy and its teaching, one must first and foremost analyze the behavior of teachers in an attempt to visualize how they shape their teaching choices. According to Kalantzis et al. (2019), if we are to have 'new', 'modern' students we need nothing less than 'new', 'modern' teachers to work with students, with parents and with each other by expanding and promoting 'literacy' learning practices towards learning "literacies" to create learners capable of deriving, producing meaning and communicating.

Research conducted internationally (Snow, Burns, \& Griffin 1998, Strickland \& Shanahan 2004, Powell et al. 2008, Heath 2009, Hindman \& Wasik 2011, Scull, Nolan, \& Raban 2013) but also in Greece (Tafa 2001, Giannikopoulou 2001, Papoulias-Tzelepi 2001, Porpodas 2002, Kondylis \& Stellakis 2006, Aidinis \& Grollios 2007, Kostoulis 2014, Xefteris 2017) demonstrates that early language stimulation have great importance for reading development and children's literacy learning occurs through actions that have a meaning for them and a clear purpose. These studies on literacy practices of kindergarten (4-6 years old in Greece) and first grade literacy practices (6-7 years old in Greece), categorize kindergarten teachers and first-grade primary school teachers in two categories ${ }^{13}$. The first one is those who have a tendency to adopt the principles and practices of the holistic approach and the second is those who adopt the systematic code teaching principles to enhance literacy. In their results they found a significant distribution of teachers' practices in the two aforementioned categories, which are directly related to their perceptions (Fang 1996, Pedersen \& Liu 2003). In particular, researchers point out that perceptions, values, the social and ideological context, the theoretical underpinnings and the teaching approaches suggested by the curricula, experience (Burgess et al. 2001, LoCasale-Crouch et al. 2007), specialization ${ }^{14}$

\footnotetext{
13 In Greece, kindergarten teachers and primary school teachers received an equal education (University Education) and their wages are at the same level

${ }^{14}$ Researchers have found that teachers-holders of a master's degree place greater emphasis on oral speech in their classrooms compared to teachers who hold a bachelor's degree, see: Burgess et. al. 2001
} 
(Burgess et al. 2001) should always be taken into account in the study and record keeping of literacy enhancing practices adopted by teachers in their classrooms (Yero 2002).

In this context, a successful balanced approach to literacy requires the teacher on one hand to combine approaches, methods and techniques to become more effective for his students and on the other hand to stay informed, to train and collaborate (Hall, 2003). An important aspect of the effectiveness of the educational work for learners is their smooth transition from one grade to another, which can be greatly facilitated if teachers from one grade, such as the kindergarten, cooperate with those in the next grade, that is, elementary school and vice versa. Collaboration and continuity between school types are important factors that favor long-term learning and that need to be given attention in the transition between early childhood school institutions (Bredekamp \& Copple 1997, Pianta et al. 1999, Rimm-Kaufman \& Pianta 2000, Early 2004, Broström 2007, Dockett \& Perry 2007, Fabian \& Dunlop 2007, Ecclestone 2009, Ackesjö 2013, Ahtola et al. 2011, Alatalo, Meier, \& Frank 2016, Alatalo, Meier \& Frank 2017). Collaboration between pre-school, primary school and parents is considered the most important factor in confronting the difficulties of the transition (Alatalo et al. 2017). "The continuity" between the two educational institutions related directly with the development of normal transition (Dunlop \& Fabian, 2002). The aims, the goals and the curriculum of the pre-school and the primary school must have been compatible to ensure this continuity (Vrinioti 2008). According to the Greek curricula (2003) children's language development is one of the prioritized target areas. An important part of the task of the preschool is to stimulate each child's language development and to encourage and protect the child's curiosity and interest in the written language. The teachers in preschool and primary school settings must exchange knowledge and experiences about children's learning as to support and encourage every child's long-term development and learning.

The key factor to this continuity is that kindergarten and primary school teachers should work together to continue the philosophy, pedagogical approaches, and teaching practices from one grade to another. In particular, in a context of collaboration and exchange of views, one expects the adaptation of teaching practices to a common practice and the alignment of teachers' expectations and requirements of their students. A strong and equal partnership between pre-school and primary school as an educational continuity and flexibility in early childhood education must be aimed by developing a common pre-school and primary school, communicative-teaching approach in early literacy and language practice within a participatory approach. Teachers in both pre-schools and primary schools need to encourage language acquisition and early literacy approaches. Only in such a framework of shared approaches, perceptions and practices can students work without continuity being interrupted.

And while one would expect that kindergarten and school teachers would have realized the benefits of working together both for the benefit of their pupils and their teaching practice, but also for themselves, the problem of collaboration, although quite old, seems to still exist, according to the researchers (Bredekamp \& Copple 1997, Pianta, et al. 1999, Rimm-Kaufman \& Pianta 2000, Broström 2002, Margetts 2002, Early 2004, Broström 2007, Dockett \& Perry 2007, Fabian \& Dunlop 2007, Niesel \& Griebel 2007, Vrinioti 2008, Ecclestone 2009, Sivropoulou \& Vrinioti 2009, Ackesjö 2013, Ahtola et al. 2011, Karydis 2014, Alatalo et al. 2016, Alatalo et al. 2017). In these studies has been proven that lack of communication and effective collaboration between preschool and primary school is an important barrier to continuity. For example, some studies (Hjelte 2005, Ackesjö 2013, Alatalo et al. 2016) report that kindergarten teachers and primary school teachers do not speak the same language and make different interpretations of the information and formulations that are presented. As Alatalo et al. referred (2017: 4) "in such circumstances, there is a risk that knowledge of the children's skills, abilities, and prior experiences are also given little or no attention. The interaction between those two institutions has been found to be almost nonexistent. The distance between the institutions is perceived as great and the collaboration between the two in many cases does not occur". Lacks of time and of natural 
arenas for cooperation were the reasons for no interaction (Pianta et al. 1999, Hjelte 2005, Ackesjö 2012, Alatalo et al. 2016, Alatalo et al. 2017).

In the same context in Greece, according to Karydis (2014), cooperative practices between kindergarten and primary school teachers are rarely observed, perhaps demonstrating a lack of knowledge of the positive effects of such cooperation. The factors that make this cooperation difficult, accordingly to international researches, appear to be: a) time, b) space, and c) lack of initiative as to who should take the first step (Pantazis 1991: 57). According to Brostom (2002), kindergarten teachers seem to have limited knowledge of what is going on in the school classroom and may believe that things haven't changed since they went to school. Similarly, teachers teaching in the first grade of primary school seem to treat preschools as childcare facilities rather than educational facilities. According to Alatalo et al. (2017) the kindergarten's teachers' wishes to know more about the children's literacy learning are too much on a general level to be able to provide a good enough basis for planning literacy activities that fit every individual child. In the same context, results of this research demonstrate that preschool tradition has viewed care as being core to its work and considered learning and achievement as domains associated with compulsory school.

Co-operation could possibly promote the modification of the perceptions of kindergarten and school teachers. According to Bredekamp and Copple's (1997) research, collaboration could be implemented through visits to the next grade, as they help children better adapt, through teachers' meetings and discussions of the differences and similarities in curricula for which they could prepare children, by informing each other about every individual pupil, as the kindergarten teacher's knowledge of each child could help the teacher better cope with their task. Getting to know the way previous or next level colleagues work will help teachers to draw useful conclusions, while understanding how each level works and its difficulties, will cause them to find solutions together. Perhaps, eventually, teacher-to-teacher collaboration will be a powerful link to smooth the transition of children to elementary school and continuity through a balanced literacy curriculum; the direction; provided that educators realize it and work towards that end.

This research gap, identified in international and Greek literature, which concerns the study of perceptions of first-grade primary school teachers and kindergarten teachers on the issue of cooperating with one another on literacy practices, is what this paper seeks to address.

\section{Methodology}

The lack of communication and effective collaboration between preschool and primary school is an important barrier to continuity of literacy teaching and learning was demonstrated from many researchers (Bredekamp \& Copple 1997, Pianta et al. 1999, Rimm-Kaufman \& Pianta 2000, Broström 2002, Margetts 2002, Early 2004, Broström 2007, Dockett \& Perry 2007, Fabian \& Dunlop 2007, Niesel \& Griebel 2007, Vrinioti 2008, Ecclestone 2009, Ackesjö 2013, Ahtola et al. 2011, Karydis 2014, Alatalo et al. 2016, Alatalo et al. 2017). In this context the purpose of this research is to study the perceptions of Greek first-grade primary school teachers and kindergarten teachers about the need for and the existence of co-operation, ways to achieve it, as well as the benefits of collaboration on literacy, literacy practices and its reinforcement.

The research was conducted using a self-administered questionnaire (survey-monkey) ${ }^{15}$. A pilot study was conducted on a sample of 10 kindergarten teachers and 10 primary school teachers in order to identify any ambiguities in the content of the questionnaire. The questionnaire was organized into 8 study areas with closed and open-ended questions. For the purposes of the research, the 6th pillar of the questionnaire is presented, which examines the perceptions of kindergarten and school teachers about

\footnotetext{
15 The improvised questionnaire was developed based on the theoretical framework of the thesis. Only the axis and the questions we are interested in are presented here
} 
the need for collaboration among them in enhancing literacy, its potential benefits and ways of achieving collaboration between them. It also explores the practices and perspectives adapted by kindergarten and school teachers in working together to enhance literacy and the potential benefits of such collaboration. In addition to assessing teachers' beliefs and practices, the questionnaire requests information about the teachers' educational background, teaching experience, and school/classroom characteristics (e.g., colocated schools, are of the school, number of students/teachers).

Specifically, closed-ended questions examined their agreement / disagreement (5-point Likert scale: not at all, a little, quite a lot, a lot, very much) to these research questions: a) "To what extent do you think that first grade teachers in elementary school should cooperate with kindergarten teachers on literacy enhancing ", b) "To what extent do you believe that first grade teachers of elementary school cooperate with kindergarten teachers for literacy enhance", and/or multiple choice/open-ended questions examined their perceptions to these research questions c) "Identify the ways in which you believe that first-grade primary school teachers and kindergarten teachers can work together regarding language enhancing", d) "Cooperation between kindergarten and first grade teachers in elementary school on literacy can be more beneficial for the student, the teacher or the curriculum"?

The data processing techniques utilized quantitative research on closed-ended questions and qualitative research on open-ended question, in order to investigate and understand in depth the stated agreement/disagreement and their proposals. We analyzed quantitative research data with the statistical package SPPS 25 ( $t$ test, $F, x^{2}$ ) in relation to the major questions, providing a descriptive analysis of teacher's perceptions and practices self-reported practices in terms of percentages, means, and standard deviations. To assess common features of kindergarten and primary school teachers' beliefs and practices, we performed separate factor analyses (using principal axis methods with varimax rotations). Additionally, we compared selected teacher characteristics and the derived belief and practice factors using analysis of variance or correlations with alpha set at $p<.05$. For qualitative research data from open-ended question we used the content analysis method having the content of the sentence/phrase as a unit of analysis (Creswell 2016).

The study involved 632 educators, serving Greek public schools of a particular geographical area (two regions), in two groups as the sample of this research. The first one was 326 kindergarten teachers, and the second was 306 school teachers teaching the year of the process in the first grade of Greek primary schools. The sample was selected by simple random sampling, which is one of the probability sampling types (Cohen \& Manion 2008, Creswell 2016). However, the sample size and the geographical limitation of the survey did not allow us to generalize the results. There may be differences in their perceptions and practices from region to region. Nevertheless, we believe that the findings should not lose their relevance but should serve as a basis for further relevant investigations.

In terms of school teachers gender, the $243(79.4 \%)$ teachers teaching in the first grade of Greek primary schools are women and $63(20.6 \%)$ are men, while the 325 kindergarten teachers (99.7\%) are women. $85 \%$ of teachers and $88.3 \%$ of kindergarten teachers have basic studies, while $15 \%$ of teachers and $11.7 \%$ of kindergarten teachers have additional studies. Teachers (88.2\%) and kindergarten teachers $(84 \%)$ are employed as permanent educators. $43.1 \%$ of teachers have served from $0-10$ years, $30.4 \%$ from $11-20$ years, and $26.5 \%$ over 20 years. Of kindergarten teachers, respectively, $50.6 \%$ have served from $0-10$ years, $31.8 \%$ from $11-20$ years and $17.6 \%$ more than 20 years. 181 (59.2\%) first grade primary school teachers and 182 (55.8\%) kindergarten teachers serve in urban schools, while $20 \%$ of primary school teachers and kindergartener teachers serve in semi-urban or rural schools (rural areas).

In designing and conducting the research we have taken into account ethical issues and ethics (Miles \& Huberman 1994, Fontana \& Frey 1998, Cohen et al. 2008, Bryman 2017). The questionnaires were accompanied by a letter stating the purpose of the research, the value of participation, the anonymity of participants and that the results of the research will be informed. 


\section{Results}

1. Perceptions about the need for collaboration between kindergarten and school teachers on literacy enhance.

Regarding the question "To what extent do you think that first grade teachers in elementary school should cooperate with kindergarten teachers on literacy enhance", 113 kindergarten teachers (34.7\%) and 64 teachers teaching in the first grade of primary school (20.9\%) reply "very much", 98 (30.1\%) kindergarten teachers and 116 teachers teaching in the first grade of primary school (37.9\%) reply "a lot". In fact, this difference between kindergarten and primary school teachers is statistically significant (Cramer's $\mathrm{V}=0.162, \mathrm{x} 2=16.485, \mathrm{df}=4, \mathrm{p}<0.05)$. There are many more kindergarten teachers who support the need for literacy collaboration with primary school teachers (table 1).

Table 1: Perceptions about the need of cooperation.

To what extent do you think that first grade teachers in elementary school should cooperate with kindergarten teachers on literacy enhance

\begin{tabular}{c|c|c}
\hline & Kindergarten teachers & School teachers \\
\hline Not at all & $5(1.5)$ & $10(3.3)$ \\
\hline A little & $22(6.7)$ & $26(8.5)$ \\
\hline Quite a lot & $88(27.0)$ & $90(29.4)$ \\
\hline A lot & $98(30.1)$ & $116(37.9)$ \\
\hline Very much & $113(34.7)$ & $64(20.9)$
\end{tabular}

To examine how teacher's characteristics were related to their perceptions and practices, we compared the derived perceptions and practices factors and the following characteristics: years of teaching experience, level of teacher education, co-location and area of school. Using analysis of variance (ANOVA), a comparison between the years of teaching experience and co-location of schools their beliefs factors yielded significant differences among the groups on their beliefs about the need of cooperation. Specifically, the kindergarten teachers with the most years of service were much more positive $(43.1 \%)$ about the need for cooperation, while among teachers teaching in the first grade of primary school, those whose school was co-located with a kindergarten seemed to agree more with the need for cooperation. (Cramer's $V=0,181 . x 2=10.035, d f=4, p<0.05$ ).

2. Perceptions about the existence of collaboration between kindergarten and school teachers on literacy enhance

In the question "To what extent do you believe that first grade teachers of elementary school cooperate with kindergarten teachers for literacy enhance", 201 kindergarten teachers (61.7\%) said 'not at all', that is, no cooperation whatsoever, 101 (31\%) responded 'a little', that is, a little cooperation, while only 18 (5.5\%) answered 'quite a lot'. Primary school teachers showed a relative modesty with 140 (45.8\%) responding 'a little', 107 (35\%) saying 'quite a lot', and 36 (11.8\%) responding 'a lot' (table 2). This difference between kindergarten and school teachers is statistically significant (Cramer's $V=0.648$, $\mathrm{x} 2=265,273, \mathrm{df}=4, \mathrm{p}<0.001)$. In other words, kindergarten teachers, when asked about their perception of the need to work with teachers to enhance literacy, appeared to be positive and supportive of such a perspective; when asked however about their awareness of the existence of such co-operation they were very negative. On the contrary, while teachers were more restrained about the need to work with kindergarten teachers to enhance literacy, they seemed to believe more strongly that they do work together. 
Table 2: Perceptions about cooperation.

To what extent do you believe that first grade teachers of elementary school cooperate with kindergarten teachers for literacy enhance

\begin{tabular}{c|c|c}
\hline & Kindergarten teachers & School teachers \\
\hline Not at all & $201(61.7)$ & $13(4.2)$ \\
\hline A little & $101(31.0)$ & $140(45.8)$ \\
\hline Quite a lot & $18(5.5)$ & $107(35.0)$ \\
\hline A lot & $5(1.5)$ & $36(11.8)$ \\
\hline Very much & $1(.3)$ & $10(3.3)$
\end{tabular}

The correlation of the responses of kindergarten and school teachers to this question with the variable "school unit co-location" showed that the kindergarten teachers whose unit is co-located with a primary school stated that they agreed a little (34.4\%) or quite a lot (8.6\%) with the existence of collaboration; compared to the teachers who, when their school is co-located with a kindergarten, say that they agree quite a lot $(40.3 \%)$ and a lot (14.8\%) with the existence of collaboration. Specifically, kindergarten teachers whose school is co-located with a primary school express a disappointment as they find that co-operation is non-existent, unlike teachers who believe co-operation significantly thrives through co-location.

3. Perceptions about ways to achieve collaboration

In the question "Identify the ways in which you believe that first-grade primary school teachers and kindergarten teachers can work together regarding literacy enhance", kindergarten and primary school teachers were asked to respond positively or negatively to each of the proposed ways, while they were given the opportunity to submit further proposals, that is, ways of achieving cooperation between kindergarten and primary school teachers (table 3).

Table 3: Cooperation practices - Kindergarten teachers.

\begin{tabular}{l|c|c|c}
$\begin{array}{c}\text { Kindergarten } \\
\text { teachers }\end{array}$ & $\begin{array}{c}\text { Analysis of objectives } \\
\text { and teaching practices } \\
\text { for teaching language } \\
\text { at each level }\end{array}$ & $\begin{array}{c}\text { Submission of individual } \\
\text { learners portfolios by } \\
\text { kindergarten teachers to } \\
\text { school teachers and } \\
\text { comprehensive examination } \\
\text { of them }\end{array}$ & $\begin{array}{c}\text { Organization of classroom space } \\
\text { by teachers of both levels in } \\
\text { the light of a common } \\
\text { perspective for enhancing } \\
\text { functional reading }\end{array}$ \\
\hline Yes & $198(60.7)$ & $171(52.5)$ & $224(68.7)$ \\
\hline No & $128(39.3)$ & $155(47.5)$ & $102(31.3)$
\end{tabular}

In the 'Analysis of objectives and teaching practices for literacy enhance at every level', 198 kindergartens (60.7) responded positively, while 128 (39.3) stated no. 171 kindergartens (52.5\%) responded positively to 'Submission of individual learners' portfolios by kindergarten teachers to school teachers and comprehensive examination of them', while 155 (47.5\%) responded negatively. In the proposed way 'Organization of classroom space by teachers of both levels in the light of a common perspective for enhancing functional reading', 224 teachers (68.7\%) agreed, while 102 (31, 3\%) of them do not consider it as a sufficient way to achieve cooperation.

What was also noteworthy was the kindergarten teacher's eagerness to suggest ways in which kindergarten teachers and school teachers could work together for language education. Here are some answers:

- Mutual visits - joint activities and games

- Ongoing briefing and feedback

- Meetings with parents and teachers of both levels; 
- Develop and implement joint activities focusing on linguistic objectives;

- A joint project with many common language activities and co-teaching at least once a month with visits exchange;

- Consideration by teachers of kindergarten work (most do not know that our classroom is divided into "corners");

- It could be more clearly stated in the curricula what preschoolers should acquire on a linguistic level;

- There must be a redefinition of cognitive goals at 2 levels;

- There may be cooperation if schools are co-located or in a close distance.

Kindergarten teachers seem to find it important to implement joint actions, the constant interaction between them, the teachers' greater interest in the kindergarten and the work being done to enhance natural literacy. They pose co-location and distance as an important variable that affects and determines the degree of co-operation. At the same time, they seek to redefine cognitive goals in the two school levels in order to achieve the required cooperation, and to clarify the required level of language acquisition of infants upon completion of kindergarten.

The answers of primary school teachers are quite different (table 4). 174 primary school teachers (56.9\%) responded positively to 'Analysis of objectives and teaching practices for teaching language at each level ', while 132 (43.1\%) responded negatively, with primary school teachers who stated that their school is co-located with a kindergarten more (64.45) in agreement with this proposal. 196 (64.1\%) responded positively to the 'Submission of individual learners' portfolios by kindergarten teachers to primary school teachers and comprehensive examination of them' and 110 (35.9\%) indicated a negative attitude. With the proposed way to achieve collaboration 'Organization of classroom space by teachers of both levels in the light of a common perspective for enhancing functional reading', 139 teachers (45.4) showed agreement, while 167 (54.6) ) do not consider it as a sufficient way to achieve cooperation, with teachers with additional university studies $(60.9 \%)$ responding more positively.

Table 4: Cooperation practices - primary school teachers.

\begin{tabular}{l|c|c|c}
$\begin{array}{c}\text { Primary } \\
\text { School } \\
\text { teachers }\end{array}$ & $\begin{array}{c}\text { Analysis of objectives } \\
\text { and teaching practices } \\
\text { for teaching language } \\
\text { at each level }\end{array}$ & $\begin{array}{c}\text { Submission of individual learners } \\
\text { portfolios by kindergarten } \\
\text { teachers to school teachers and } \\
\text { comprehensive examination of } \\
\text { them }\end{array}$ & $\begin{array}{c}\text { Organization of classroom } \\
\text { space by teachers of both } \\
\text { levels in the light of a common } \\
\text { perspective for enhancing } \\
\text { functional reading }\end{array}$ \\
\hline Yes & $174(56.9)$ & $196(64.1)$ & $139(45.4)$ \\
\hline No & $132(43.1)$ & $110(35.9)$ & $167(54.6)$
\end{tabular}

Kindergarten and school teachers exhibited the same moderation in analysis of objectives and teaching practices for teaching language at each level, since their responses did not appear to differ significantly $(x 2=0.978, \mathrm{df}=1, \mathrm{p}>0.05)$. However, they were statistically significantly (Cramer's $\mathrm{V}=$ $0.117, \mathrm{x} 2=8.720, \mathrm{df}=1, \mathrm{p}<0.05$ ) more positive about the submission of individual learners' portfolios by kindergarten teachers to school teachers and comprehensive examination of them. Statistically significant (Cramer's V $=0.235, \mathrm{x} 2=35.012, \mathrm{df}=1, \mathrm{p}<0.001$ ) was teachers' more negative attitude, compared to kindergarten teachers, in organization of classroom space by teachers of both levels in the light of a common perspective for enhancing functional reading as a proposed way of achieving cooperation.

The eagerness of the interviewed primary school teachers to propose ways of achieving collaboration on literacy enhance was not as positive as that of the kindergarten teachers.

However, their few answers are typical:

- Exchange visits, joint actions mainly at the beginning of the school year, although we are limited in time by course material; 
- Meetings between first grade teachers - kindergarten teachers, although there is no common time;

- A joint project could be implemented involving both pupils of the first grade and kindergarten;

- Kindergarten teachers' oral briefing on the performance of each learner;

- Specific and defined teaching objectives at each level and collaboration at each level to define these objectives;

- The book of the 1 st grade is demanding. It is therefore necessary that they have practiced on prewriting exercises. This will especially help students with learning disabilities.

School teachers want common actions and meetings with the kindergarten teachers to be verbally informed about the performance of each preschooler, also clear identification of the kindergarten and first grade teaching objectives, so that the desired cooperation can be achieved. They refer to the lack of time and pressure they feel themselves from the curriculum, an important variable not highlighted by kindergarten teachers, whose schedule is by definition more flexible.

An important finding of this research is a teacher's suggestion to teach children in kindergarten with pre-writing exercises, as the first grade language book is quite demanding. On the one hand, it exhibits a lack of knowledge of the abolition of pre-writing exercises in kindergarten and on the other hand it seems to be misinterpreting the perception of kindergarten work as preparatory to the entry of children into primary school.

3. Perceptions about the advantages of collaboration

Then this question was posed: "Cooperation between kindergarten and first grade teachers in elementary school on literacy can be beneficial." Kindergarten and primary school teachers had to choose from the following options:

- For the educational process;

- For the first grade teacher of the elementary school;

- For the kindergarten teacher;

- For first grade students;

- For Kindergarten students;

- To achieve the curriculum linguistic goals (a cross thematic curriculum framework for Kindergarten) in the kindergarten;

- To achieve the linguistic goals in the first class of primary school.

To study the variations of their responses we coded them in three new variables "the curriculum", "the teacher" and "the student". Based on the new categories, average and standard deviation of responses for kindergarten and primary school teachers were stated separately.

For kindergarten teachers (table 5 ) "the student" (Average $=2.76$, Standard Deviation $=1.20$ ) was declared as the most important, followed by "the curriculum" (Average $=4.12$, Standard Deviation $=$ 1.19) and "the teacher" (Average $=4.63$; Standard Deviation $=1.76$ ).

Table 5: Perceptions about the advantages of collaboration - kindergarten teachers.

\begin{tabular}{c|c|c|c}
$\begin{array}{c}\text { Kindergarten } \\
\text { teachers }\end{array}$ & Curriculum & Teacher & Student \\
\hline Mean & 4.1248 & 4.6301 & 2.7632 \\
\hline Median & 4.0000 & 4.5000 & 2.5000 \\
\hline Std. Deviation & 1.19963 & 1.76477 & 1.20484 \\
\hline Range & 4.00 & 5.00 & 5.00 \\
\hline Minimum & 2.00 & 1.50 & 1.50 \\
\hline Maximum & 6.00 & 6.50 & 6.50
\end{tabular}


For school teachers (table 6) "the student" (Average $=2.81$, Standard Deviation $=1.23$ ) was declared as the most important, while in order of importance "the curriculum" (Average $=4.39$, Standard Deviation $=1.06$ ) and "the teacher" (Average $=4.34$, Standard Deviation $=1.42$ ) followed.

Table 6: Perceptions about the advantages of collaboration - primary school teachers.

\begin{tabular}{c|c|c|c}
$\begin{array}{c}\text { Primary school } \\
\text { teachers }\end{array}$ & Curriculum & Teacher & Student \\
\hline Mean & 4.3997 & 4.3442 & 2.8107 \\
\hline Median & 4.6667 & 4.5000 & 2.5000 \\
\hline Std. Deviation & 1.06482 & 1.42857 & 1.23615 \\
\hline Range & 4.00 & 5.00 & 5.00 \\
\hline Minimum & 2.00 & 1.50 & 1.50 \\
\hline Maximum & 6.00 & 6.50 & 6.50
\end{tabular}

However, their responses differed significantly for both "the teacher" $(t=3.153, d f=229, p<0.05)$ and "the student" ( $t=2.562, \mathrm{df}=241, \mathrm{p}<0.05)$, depending on whether the primary school teachers stated that the school they serve is co-located with a kindergarten. The correlations of the variables showed that school teachers who stated that their school was co-located with a kindergarten placed less emphasis on "the teacher" (Average $=4.63$, Standard Deviation $=1.41$ ) and greater emphasis on "the student" (Average $=2.61$, Standard Deviation $=1.17$ )

\section{Discussion}

The research is aimed at investigating the perceptions of first-grade Greek primary school and kindergarten teachers on the issue of working together to enhance literacy.

The problem of collaboration, stated by a number of researchers (Bredekamp \& Copple 1997, Pianta et al. 1999, Rimm-Kaufman \& Pianta 2000, Broström 2002, Margetts 2002, Early 2004, Broström 2007, Dockett \& Perry 2007, Fabian \& Dunlop 2007, Niesel \& Griebel 2007, Vrinioti 2008, Ecclestone 2009, Sivropoulou \& Vrinioti 2009, Ahtola et al. 2011, Karydis 2014, Alatalo et al. 2017) demonstrated clearly by our research findings. Accordingly to international studies (Hjelte 2005, Ackesjö 2013, Karydis 2014, Alatalo et al. 2016) our findings stated that kindergarten and school teachers don't seem to have realized the benefits of working together. Although kindergarten teachers seem more favorably disposed towards the need for first-grade primary school teachers and kindergarten teachers to collaborate on literacy and its approach in the classroom, with the more experienced kindergarten teachers and the school teachers whose school is co-located with a kindergarten to be more positive towards cooperation.

Lacks of time and of natural arenas for cooperation were the reasons for no interaction (Pantazis 1991, Pianta et al. 1999, Hjelte 2005, Ackesjö 2012, Alatalo et al. 2016, Alatalo et al. 2017) were absolutely confirmed by our findings. Perceptions of first grade teacher's for preschools as childcare facilities rather than educational facilities (Brostom 2002) were also confirmed by our findings.

In terms of depicting the reality of kindergarten and primary school teacher collaboration to enhance literacy, kindergarten teachers responded very negatively while school teachers were more unassuming about it. Kindergarten teachers, even when their school is co-located with a primary school, express a strong disappointment, as they claim that despite co-location, co-operation is non-existent, unlike teachers who believe co-operation significantly thrives through co-location.

These responses show the willingness and flexible attitude of kindergarten teachers to modify their practices, their space, but also their philosophy for the benefit of the educational practice and enhancing literacy, while teachers seem to consider sufficient to simply to be updated by kindergarten teachers and the given the students' portfolios in order to formulate their expectations and requirements of young 
students. This finding is also confirmed by the answers given by kindergarten and school teachers to the open question that enabled them to propose ways of working together to enhance literacy. Specifically, kindergarten teachers respond and propose more cooperative practices, while teachers insist on emphasizing limiting factors in their cooperation, such as lack of time and the pressure they feel from the course material they need to cover.

In the question about those who benefit from a potential collaboration, kindergarten teachers and school teachers agreed in their responses, believing that students benefit more, then the educational process, and less they themselves. According to Bredekamp and Copple's (1997) research, collaboration could be implemented through a context of student-centered teaching and learning, kindergarten and school teachers go hand in hand, at least on a theoretical level, on the pursuit of practices of enhancing natural literacy for the benefit of students and facilitating the learning process.

\section{Conclusion}

In conclusion, while there are convergence points in the perceptions of kindergarten teachers and primary school teachers about their co-operation on enhancing literacy, they also appear to have different views which are reflected in their adopted practices. While there seems to be some willingness to change and create a framework for collaboration by kindergarten teachers, however, school teachers appear to be more satisfied with the situation as it is now, expressing their doubts about a possible broader collaboration due to lack of time and course material pressure. At this point, a strong need for continuous and systematic training of teachers on contemporary teaching issues is demonstrated, which would highlight the need for a cooperative kindergarten and elementary school framework.

It is within this framework that the need for a combination of the two Greek curricula (2003) emerges, in order to demonstrate their relevance as well as the continuity that should exist in the practices proposed to be adopted by teachers at both levels. Organizing an institutional framework for interaction between the two educational levels, creating learning communities and adopting methodological approaches based on action-research, would create a framework that could function as a bridge between kindergarten and elementary school with obvious positive outcomes for young students, teachers and the school community at large.

The research findings highlight the convergence and divergence of views and practices of Greek kindergarten and primary school teachers on their collaboration to enhance literacy development. The geographical limitation of research, which took place in a specific geographical area of Greece and a limited number of the survey population, does not allow us to generalize the results. However this research must be considered a first short-range investigation of the opinion that mixed groups of preschoolers and first graders improve students' literacy to some extent. It would be useful to repeat the research by drawing a larger representative sample of teachers and other areas without geographical limitations would be of particular interest in highlighting the intensity of the relationship between physical and school literacy, as reflected in perceptions, as well as the cooperative practices of kindergarten teachers and primary school teachers.

The results could constitute the pillars for institutionalizing a more co the goal is to have continuity through a balanced literacy curriculum and smooth transition of children to elementary school. The results could be the pillars for establishing a framework for teacher collaboration to continue the learning of literacy through a balanced literacy program and smooth transition of children to elementary school.

\section{References}

Ackesjö, H. (2013). Children crossing borders: School visits as initial incorporation rites in transition to preschool class. International Journal of Early Childhood, 45, 387-410, doi: 10.1007/s13158-013-0080-7. 
Ahtola, A., Silinskas, G., Poikonen, P., Kontoniemi, M., Niemi, P. $\quad$ \& Nurmi, J. $\quad$ E. (2011). Transition to formal schooling: Do transition practices matter for academic performance? Early Childhood Research Quarterly, 26, 295302, doi:10.1016/j.ecresq.2010.12.00.

Aidinis, A. \& Grollios, G. (2007). Critical remarks in the new book of the first grade language lesson of the Elementary School. Antitetradia tis ekpaidefsis, 85, 35-42.

Alatalo, T., Meier, J. \& Frank, E. (2017). Information sharing on children's literacy learning in the transition from Swedish preschool to school. Journal of research in childhood education, 31 (2), 240-254.

Alatalo, T., Meier, J. \& Frank, E. (2016). Transition between Swedish preschool and preschool class: A question about interweaving care and knowledge. Early Childhood Education Journal, 44 (2), 155-167.

Bredekamp, S. \& Copple, C. (1997). Developmentally Appropriate Practice in Early Childhood Programs (Revised Edition). Washington, DC: NAEYC.

Broström, S. (2002). Communication and continuity in the transition from kindergarten to school, in: H. Fabian, \& A.-W. Dunlop (Eds.) Transitions in the early years. Debating continuity and progression for children in early education. London: Falmer, 52-63.

Broström, S. (2007). Transitions in children's thinking, in: A.-L. Dunlop \& H. Fabian (Eds.) Informing transitions in the early years. Research, policy and practice. Maidenhead, England: McGraw-Hill/Open University Press, 61-73.

Bryman, A. (2017). Methods of social research. Athens: Gutenberg.

Burgess, K. A., Lundgren, K. A., Lloyd, J. W. \& Pianta, R. C. (2001). Preschool teachers' self-reported beliefs and practices about literacy instruction (CIERA Report 2e 012). Retrieved from: http://www.ciera.org/library/reports/inquiry-2/2-012/2-012\%20front\% 20matter.html.

Cohen, L. \& Manion, L. (2008). Educational research methodology. Athens: Metehmio.

Creswell, J. W. (2016). Research in education: planning, conducting and evaluating quantitative and qualitative research. Athens: Ion.

Dockett, S. \& Perry, B. (2007). Transitions to school: Perceptions, expectations, experiences. Sydney, Australia: University of New South Wales Press.

Early, D. (2004). Services and programs that influence young children's school transitions, in: R. E. Tremblay, R.G. Barr \& R. DeV. Peters (Eds.), Encyclopedia on early childhood development. Montreal, Canada: Centre of Excellence for Early Childhood Development, 1-4. Retrieved from http://www.childencyclopedia.com/documents/EarlyANGxp.pdf

Ecclestone, K. (2009). Lost and found in transition: Educational implications of concerns about "identity," "agency," and "structure.", in: J. Field, J. Gallacher \& R. Ingram (Eds.), Researching transitions in lifelong learning. London, England, \& New York, NY: Routledge, 9-27.

Fabian, H. \& Dunlop, A.-W. (2007). Outcomes of good practice in transition processes for children entering primary school (Working paper 42 in Early Childhood Development). Retrieved from http://www.bernardvanleer.org/Outcomes of good practice in transition processes for children enteri ng primary school

Fang, Z. (1996). A review of research on teacher beliefs and practices. Journal Educational Research, (38), 47-65.

Fontana, A. \& Frey, J. (1998). Interviewing: The Art of Science, in: N. Denzin \& Y. Lincoln (Eds.). Collecting and interpreting qualitative materials. London: Sage, 47-78.

Giannikopoulou, A. (2001). P Like Pokemon: Familiarizing children with letters in a two alphabet society, in: P. Papoulia-Tzelepi (Ed.), The Emergence of Literacy: Research and Practice. Athens: Kastaniotis, 169-195.

Hall, K. (2003). Effective literacy teaching in the early years of school: A review of evidence, in: N. Hall, J. Larson, \& J. Marsh (Eds.), Handbook of Early Childhood Literacy, Sage Publishing, 315-326.

Heath, S. B. (2009). Ways with words. Cambridge, England: Cambridge University Press.

Hindman, A. H. \& Wasik, B. A. (2011). Exploring Head Start teachers' early language and literacy knowledge: lessons from the excel PD intervention. NHSA Dialog, 14, 293-315. http://dx.doi.org/10.1080/15240754.2011.617528.

Hjelte, J. (2005). Cooperation in the border country: About the relationships and communication in collaboration between schools and childcare. Umeå, Sweden: Umeå Universitet Press.

Kalantzis, M., Cope, B., Stellakis, N. \& Arvaniti, E. (2019). Literacies. A pedagogy of diverse design and multimodal signage. Athens: Ekdoseis Kritiki.

Karydis, I. (2014). Exploring the views of kindergarten and teachers on the transition from kindergarten to elementary school: A comparative approach. (Unpublished Postgraduate Thesis), MSc, ETS, University of Ioannina. 
Kondylis, M. \& Stellakis, N. (2006). Literacy practices in pre-primary education: one program, two approaches, in: P. Papoulia-Tzelepi, A. Fterniati \& K. Thebaios (Eds.), Literature research and practice in Greek society. Athens: Ellinika Grammata, 159-180.

Kostouli, T. (2014). Identifying ways to integrate Roma children into school literacy: Negotiating dominant ideologies and differentiated teaching practices, in: E. Tresou, S. Mitakidou \& G. Karagianni, (Eds.), Proceedings of the International Conference on Integration Complexities. Publication: Research Accounts Special Account, AUTH.

LoCasaleCrouch, J., Konold, T., Pianta, R., Howes, C., Burchinal, M. \& Bryant, M. (2007). Observed classroom quality profiles in state-funded pre-kindergarten programs and associations with teacher, program, and classroom characteristics. Early Childhood Research Quarterly, 22, 3-17.

Margetts, K. (2002). Transition to school-Complexity and diversity. European Early Childhood Education Research Journal, 10 (2), 103-114. doi: 10.1080/13502930285208981

Miles, M. \& Huberman, A. M. (1994 2nd ed). Qualitative data analysis, an expanded sourcebook. London: Sage.

Ministry of Education (2003). A cross thematic curriculum framework for compulsory education. Athens: OEDB.

Ministry of Education (2003). A cross thematic curriculum framework for compulsory education for Kindergarten. Athens: OEDB.

Niesel, R. \& Griebel, W. (2007). Enhancing the competence of transition systems through co-construction, in: A. W. Dunlop \& H. Fabian (Eds.), Informing transitions in the early years. Research, policy and practice. Berkshire, UK: Open University Press, 21-32.

Pantazis, S. (1991). Problems in the transition of the child from kindergarten to school. Contemporary Education, 58, 45-58.

Papoulia-Tzelepi, P. (Ed.) (2001). The Emergence of Literacy: Research and Practice. Athens: Kastaniotis.

Pedersen, S. \& Liu, N. (2003). Teachers' Beliefs about Issues in the Implementation of a Student-Centered Learning Environment, ETR\&D, $51(2), 57-76$.

Pianta, R. C., Cox, M. J., Taylor, L. \& Early, D. (1999). Kindergarten teachers' practices related to the transition to school: Results of a national survey. Elementary School Journal, 100, 71-86. doi:10.1086/461944

Porpodas, K. (2002). Reading. Self-publishing.

Powell, D. R., Diamond, K. E., Bojczyk, K. E., \& Gerdel, H. K. (2008). Head start teachers' perspectives on early literacy. Journal of Literacy Research, 40, 422-460.

Rimm-Kaufman, S. E., \& Pianta, R. C. (2000). An ecological perspective on the transition to kindergarten: A theoretical framework to guide empirical research. Journal of Applied Developmental Psychology, 21, 491-511. doi:10.1016/S0193-3973(00)00051-4.

Scull, J., Nolan, A. \& Raban, B. (2013). Young learners: interpreting literacy practice in the preschool years. Australian Journal of Language \& Literacy, 36, 38-47.

Sivropoulou, I. \& Vrinioti, K. (2009). Early literacy in transition from pre-school to primary school: Connecting curricula. Retrieved from http://www.ease-eu.com/documents/compendium/chapter10.pdf

Snow, C., Burns, M. S. \& Griffin, P. (Eds.). (1998). Preventing reading difficulties in young children. Washington, DC: National Academy Press.

Strickland, D. S. \& Shanahan, T. (2004). Laying the groundwork for literacy. Educational Leadership, 61 (2), $74-77$.

Tafa, E. (2001). Reading and writing in preschool education. Athens: Ellinika Grammata.

Vrinioti, K. (2008). Transition of kindergarten children from kindergarten to primary school. In MNER (SMS, CSF) (Ed.) Guide to All-day Kindergarten. Athens: Patakis.

Xefteris, E. (2017). Elementary School Literacy Using Alternative Approaches: A Teaching Intervention Based on the Top-Down Teaching Model. (Unpublished PhD Thesis), Department of Primary Education, Aristotle University of Thessaloniki.

Yero, J. L. (2002). That spark. elusive Education Week. fromhttp://www.edweek.org/ew/ewstory.cfm?slug=37yero.h21 (22 December 2019). 